\title{
A PSICOTERAPIA EMDR COM ADULTOS TRAUMATIZADOS POR ABUSOS SEXUAIS INTRAFAMILIARES
}

\author{
Ana Maria Fonseca Zampieri' \\ EMDR PSYCHOTHERAPY WITH ADULTS TRAUMATIZED BY INTRAFAMILY SEXUAL ABUSE
}

\begin{abstract}
Resumo: Neste artigo a autora mostra o tratamento com psicoterapia Eye Movement Desensitization and Reprocessing (EMDR) do fenômeno sistêmico do abuso sexual intrafamiliar em pessoas que apresentam disfunções sexuais na vida adulta, tais como: anorgasmia e ejaculação prematura secundárias. Discorre sobre a invisibilidade ainda presente nas relações familiares coabusivas, da importância da contextualização e da legitimidade da subjetividade de todos os atores desse cenário traumatogênico. É apresentada sua prática clínica dos últimos quarenta anos com pessoas adultas sexualmente abusadas na infância e adolescência, de níveis socioeconômicos altos, com idades entre 14 a 58 anos, com a psicoterapia Eye Movement Desensitization and Reprocessing (EMDR). São ilustrados alguns conceitos e práticas terapêuticas. Os nomes dos adultos atendidos foram preservados. A autora ressalta a possibilidade de a psicoterapia EMDR ser uma abordagem que promove a saúde sexual de adultos traumatizados em suas famílias de origem. Pode ser realizada entre 20 e 40 sessões, dependendo da complexidade dos casos.
\end{abstract}

Palavras-chave: EMDR; trauma; abuso; sexualidade; sexo.

\begin{abstract}
In this article, the authoress shows the treatment of the systemic phenomenon of intrafamily sexual abuse, in people who present sexual dysfunctions related to the subject in their adult life, such as anorgasmia and premature ejaculation, with Eye Movement Desensitization and Reprocessing Therapy (EMDR). She discusses the invisibility that stills present in co-abusive family relationships, the importance of contextualization and the legitimacy of the subjectivity of all the authors of this traumatogenic scenario. The author presents her clinical practice with adults abused in childhood and adolescence, from high socioeconomic levels, aged 14 to 58 years, with EMDR Therapy in the last twelve years. She illustrates some concepts and practices with fictitious names of adults attended and highlights the possibility of a psychotherapy that promotes the sexual health of traumatized adults in their families of origin. Depending on the complexity of the cases, this kind of therapy performed with 20 to 40 session's shows affectivity. Keywords: EMDR; trauma; abuse; sexuality; sex.
\end{abstract}

${ }^{1}$ Psicóloga (USP). Psicoterapeuta sexual (SBRASH). Psicotraumatóloga (SaPsi). Psicoterapeuta de EMDR. Pós Doutorada, Doutorada e Mestre em Psicologia Clínica. PUC - SP. USAL - Argentina. Autora de livros e artigos da área. E-mail: anamfzampieri@uol.com.br. 


\section{Introdução}

\begin{abstract}
"Minha crença é de que o sangue e a carne sejam mais sábios do que o intelecto. O inconsciente do corpo é o lugar onde a vida borbulha em nós. É como nós sabemos que estamos vivos; vivos nas profundezas de nossas almas, e em contato com as vívidas extensões do cosmo." (LAWRENCE, 1999).
\end{abstract}

No Brasil o Disque Direitos Humanos (ou seja, o disque 100) recebeu, entre 2015 e 2016, 37 mil denúncias de abuso sexual de pessoas até 18 anos. A maioria delas $(67,7 \%)$ eram meninas na faixa etária entre 0 a 18 anos. Os meninos representavam $16,52 \%$ das vítimas. Os casos em que o sexo da criança não foi informado totalizaram $15,79 \%$. Certamente estes são números subnotificados. Há mais abusos sexuais dentro dos lares do que estes informes anunciam.

Em 18 de maio é celebrado o Dia Nacional de Combate ao Abuso e à Exploração Sexual de Crianças e Adolescentes. A data remete ao dia 18 de maio de 1973, quando Araceli Crespo, de 8 anos, foi raptada, estuprada e morta por jovens de classe média alta em Vitória (ES).

No consultório, Maria (nome fictício) trouxe-nos a queixa de anorgasmia secundária. Ela é médica, tem 42 anos, é casada há 10 anos e sem filhos. Revelou angústia ligada ao fato de ter um bom casamento, porém durante todo o relacionamento finge orgasmo para o marido, que é uma pessoa colaboradora afetivamente e ótimo parceiro, de acordo com ela. Conseguiram desenvolver vários projetos comuns de vida. Um deles é que ambos decidiram não ter filhos e congelaram óvulos caso venham a mudar de ideia algum dia. Têm um relacionamento de 12 anos, sendo 2 anos de namoro e 10 de casamento. A paciente apresenta nível socioeconômico alto, com uma família de origem do mesmo padrão, todos são universitários, trabalham na área da saúde e, inclusive, o avô paterno é médico como ela. Em uma sessão de psicoterapia EMDR (Eye Movement Desensitization and Reprocessing - Dessensibilização e Reprocessamento através dos Movimentos Oculares) surgiu uma cena do avô paterno "fazendo cosquinhas" em sua vagina embaixo da mesa da sala do jantar, o mesmo local onde ele iniciou o sexo oral em outra ocasião. Em outras sessões apareceram cenas em que ela visualizava os avanços desse avô no abuso sexual e lembrou de gostar dessas "cosquinhas" quando era criança, mas de começar a ter muita culpa após os 11 anos de idade, quando percebeu que essas "cosquinhas" eram atos perversos por parte de seu avô.

Como ampliar em nossos pacientes os vários significados dos "prazeres" corporais, mesmo em uma situação de abuso? E como a psicoterapia EMDR pode auxiliar as disfunções sexuais de adultos, que estão ligadas a abusos sexuais intrafamiliar?

A psicoterapia EMDR tem sido indicada, nos últimos anos, como tratamento para problemas de ansiedade, fobias e traumas, incluindo TEPT. Desenvolvida em 1989 por Francine Shapiro, a psicoterapia EMDR é considerada atualmente um tratamento eficaz para situações traumáticas por algumas organizações, como a American Psychiatric Association (2004) e o National Institute for Health and Clinical Excellence (2006). As mais recentes avaliações por parte da International Society for Traumatic Stress (FOA; KEANE; FRIEDMAN; COHEN, 2009) e do Department of Veterans Affairs and Department of Defense dos Estados Unidos (2010), designam a psicoterapia EMDR como um tratamento de nível excelente. É uma recomendação no nível interventivo que podemos oferecer para pacientes traumatizados em diversos níveis, incluindo os traumas sexuais (ZAMPIERI, 2014).

Em suas pesquisas, Van der Kolk et al. (2007) provou que a psicoterapia EMDR é a mais bem-sucedida para alcançar melhorias significativas no TEPT e nos sintomas depressivos em sobreviventes de traumas. Algumas meta-análises (BISSON et al., 2007; ETTEN; TAYLOR, 2008) indicam que a psicoterapia EMDR consegue efeitos terapêuticos equivalentes e duradouros como os dos métodos da abordagem cognitivo-comportamentais.

\section{O caleidoscópio do abuso sexual nas famílias}

Durante séculos, o humanismo tem nos convencido de que nós é que somos a fonte suprema de significado e que nosso livre-arbítrio é a mais alta de todas as autoridades. Em vez de esperar que alguma entidade exterior nos diga o que é o quê, somos capazes de nos basear em nossos sentimentos e desejos. (HARARI, 2016)

Jacques Rousseau (1995) afirmou que, ao buscar as regras de conduta na vida, ele as encontrou nas profundezas do seu coração, tra- 
çadas pela natureza e em caracteres que não podem ser apagados. E que é preciso que consultemos a nós mesmos sobre o que é bom ou ruim sentir. O terapeuta sexual, portanto, precisa ter seus valores revisitados constantemente para evitar reducionismos e não patologizar excessivamente, legitimando a pluralidade do sentir e as universalidades da subjetividade.

A psicoterapia EMDR trata traumas em geral; neste artigo são enfatizados os sexuais e discorridos sobre essa abordagem aplicada a esses casos.

O abuso sexual de crianças e adolescentes é um problema universal que está presente, de uma forma ou outra, em todas as culturas e sociedades e constitui um fenômeno complexo, resultando da combinação de fatores individuais, familiares e sociais. Os vastos campos incluídos estão na trama de interinfluências biológicas, psicológicas, sociais e espirituais. É possível pensar que o abuso sexual intrafamiliar cresce atualmente como consequência da perda da coesão familiar e como interesse crescente das mídias e das redes sociais? Ou apenas os casos de abuso apresentam visibilidade maior?

Ainda que se tenha conhecimento de cifras sobre este tema diariamente, paradoxalmente é possível crer que sua visibilidade apresenta um aspecto positivo, que é o de criação de diversos mecanismos de proteção a estas pessoas, bem como de programas de intervenção preventiva.

Embora os índices apontem para uma incidência de vitimas do gênero feminino, é importante ressaltar que o abuso sexual intrafamiliar também acomete meninos. Talvez os meninos apresentem maior dificuldade em revelar estes ocorridos, em função de temerem e/ou alimentarem ideias e preconceitos de que isto colocaria sua orientação sexual em questionamento. Outro mito é o de que estes abusos ocorrem com pessoas desconhecidas. Ao contrário, infelizmente, a maior frequência é encontrada no seio da família, por parentes de primeiro e segundo graus. O fato de acontecer com tantas dissimulações faz com que sua revelação seja dificultada, desacreditada e, ainda, que o sistema familiar, por diversos motivos, proteja o agressor de ser denunciado (ECHEBURUA; GUERRICA; CHEVARIA, 2007). Em uma cultura heteronormativa e sexista ainda são encontradas, em diversas famílias, crenças de que elas são sistemas privados, alimentados pela ideologia de que a mulher é propriedade do marido e os filhos são patrimônios dos pais. Abusadores sexuais intrafamilia- res, com exceções de portadores de deficiências mentais e sociais diversas, são pessoas integradas à sociedade e à família e frequentemente têm a confiança daqueles que abusam.

Outro mito é o de que as crianças provocam os adultos e, assim, são culpadas pelos abusos. Sabemos que uma das consequências do abuso sexual intrafamiliar é haver condutas hipersexualizadas e erotizadas por parte dos abusados. Ema (nome fictício), 53 anos e farmacêutica, narrou, em uma sessão de psicoterapia EMDR, em que acessou memórias infantis de abusos sexuais de seu tio materno, quando revelou, com 12 anos, para sua mãe, que lhe disse: "Se ele faz isso com você é porque você se comporta como uma prostituta. Eu me envergonho de ser sua mãe!". Essas vivências podem ser, inclusive, retraumatizantes.

Como acreditar que pais e tios biológicos cuidadosos podem ser abusadores sexuais?

Bernardo (nome fictício) tem 51 anos e é engenheiro. Em sua quinta sessão de psicoterapia EMDR relatou:

Eu levava minha sobrinha com minha filha para o clube; íamos nadar. Eu as banhava e ficava muito excitado e angustiado. Na volta, elas adormeciam no banco de trás e eu, dirigindo, com a outra mão tocava-as. Primeiro sobre as calcinhas, depois diretamente na vagina. Elas nem percebiam! Eu ficava fora de mim. A excitação me dominava.

Na décima nona sessão de psicoterapia EMDR, Bernardo já se colocava de forma diferente:

Eu tenho que respeitar os meus limites. Não posso ficar sozinho com crianças porque a situação dispara a ansiedade da minha criança machucada e abusiva. Não sou um monstro! Mas preciso ficar em estado de abstinência. Não vejo mais pornografia. Sou capaz de me controlar agora! Sei que para sempre tenho que me cuidar. É chato. Mas é isso!

Quando essa temática é abordada, frequentemente consideram-se crianças e adolescentes. Deve-se incluir, também, adultos e idosos que também protagonizam estes cenários. Em nossa prática clínica, inclusive, há pessoas abusadas sexualmente por seus cônjuges no lar em relações tóxicas, química e afetivamente. Há avós abusadas por netos em estados de toxicida- 
de ou enfermidade mentais.

Considera-se que a criança, o adolescente, o cônjuge ou o idoso são vulneráveis ao abuso sexual nas relações protetoras e amorosas. Não se percebe o improvável e o impossível.

Mauro (nome fictício), 14 anos, por exemplo, apresenta quadro de deficiência mental leve; mora com a mãe que trabalha no mercado financeiro e com a avó materna. Em sua sexta sessão de psicoterapia EMDR ele relatou:

Achei que era normal as vovós lavarem os "pintos" da gente com a boca. Mas quando contei para um amigo na escola, ele disse que minha vovó é tarada e louca. Eu achava gostoso, mas ele me ensinou a "bater punheta" e não deixar mais a minha vovó fazer isso. Daí eu contei para minha mãe!

Na décima terceira sessão de psicoterapia EMDR, Mauro relatou:

Aprendi o que são as partes íntimas, né? E a dizer não. A minha vovó é doente da cabeça, minha mãe explicou. Fico bravo se a vovó quer papo, pedir desculpas. Eu hein? Ela não pode mais me tocar, nem ficar sozinha comigo. Eu já entendi.

No caso de Mauro, é possível verificar como também é importante a psicoeducação sexual.

Há diversas estratégias de abuso, inclusive de confiança. As condutas abusivas também apresentam um espectro amplo, desde contatos físicos - diretos ou não -, bucovaginais, penianos, vaginais, anais, de exibicionismo, voyeurismo e utilização de força para produção de pornografia, entre outros. Relações de desigualdades de maturidade, de idades, de saúde mental, de poder e de explorações de diversos níveis devem ser consideradas. Falsas crenças, mitos, tabus, estigmas sociais e informações inadequadas fazem com que pesquisas de prevalência destes abusos sejam de difíceis detecções.

Embora 20\% dos casos relatados de incesto refiram-se a contatos pai-filha, eles são considerados os mais traumáticos, pois podem levar à dissolução dos laços familiares mais básicos (HERMAN; RUSSELL; TROCKI, 2006). O incesto entre padrasto e filha é responsável por $15 \%$ dos casos. Os $65 \%$ restantes envolvem irmãos, tios, irmãos, avós e namorados que vivem na mesma casa (MCCARTHY, 2002). O incesto mãe-filho é menos frequentemente revelado e está limitado a casos em que a mãe é dependente química e/ ou tem um histórico de abuso sexual na infância (LAWSON, 2013).

Geralmente o processo abusivo se inicia com carícias até evoluir para a masturbação e o contato bucogenital. Em alguns casos há evolução para a relação sexual vaginal e/ou o intercurso anal. Na ausência de vestígios pouco identificáveis, o abuso sexual em crianças geralmente fica impune (ECHEBURÚA et al., 2015).

Com relação à situação de alto risco, não há relação direta de causa e efeito, mas associações probabilísticas. É mais provável, portanto, uma criança que está em uma situação de alto risco social se torna mais vulnerável (FINKELHOR; ASDIGIAN, 2006).

Eu fui abusada pelo meu tio, meu padrinho e meu primo, dos 8 até os 16 anos. Todo mundo sabia. Eu era o lixo da "porra" deles. Ninguém ligava. Eu era feia, sem pai, com mãe bêbada. Eu era um nada. (Relato de Mônica -nome fictício -, 23 anos, faxineira, em sua terceira sessão de psicoterapia EMDR.)

Já em sua décima sessão de psicoterapia, Mônica relatou:

Já consigo me imaginar sendo mãe um dia. Eu posso escolher melhor meus parceiros né? Eu que posso fazer que me respeitem. Sou eu que digo se quero ou não "trepar" com eles. Posso ser gente de valor.

Crianças que vivem em ambiente de alto risco, privadas de carinho na família, inicialmente se sentem lisonjeadas com a atenção que recebem, porém esse prazer, ao longo do tempo, produzirá nelas um profundo sentimento de culpa. As que são vítimas de maus-tratos, sob qualquer forma, são mais propensas a se tornar vítimas de abuso sexual, provavelmente devido a sua baixa auto-estima e vulnerabilidade aos enfrentamentos com limites adequados. Neste artigo, abordam-se abusos em que não necessariamente há violências e coerções físicas.

É fato afirmar que crianças e adolescentes abusados sexualmente por familiares e que pertencem à classe social alta são mais invisíveis para as autoridades e terapeutas que outras crianças. Apesar de apresentarem melhor qualidade de vida, seus pedidos de socorro são raramente ouvidos, talvez por serem socialmente 
mais "protegidas" e distantes de serviços sociais. Pessoas dessas classes sociais queixam-se frequentemente de, ao revelar seus abusos, serem desacreditadas.

As repercussões psicopatológicas do abuso sexual intrafamiliar com efeitos negativos psicológicos a curto, médio e longo prazo terão impactos maiores ou menores dependendo de vários fatores, entre eles as diferenças individuais, apoios recebidos durante as revelações e após elas.

Dentre os fatores de vulnerabilidade é preciso considerar o tipo de abuso - agudo ou crônico -, os tipos de ameaças e os tipos de contatos físicos - diretos ou não. Igualmente é preciso avaliar o nível de relacionamento com o abusador, as reações das famílias e os graus de ambientes disfuncionais.

Estudos sobre adultos abusados na infância (INTEBI; OCHOTORENA, 2008), relatam encontrar prostitutas que fugiram de casa por abusos sexuais intrafamiliares, assim como adolescentes dependentes químicos que também fugiram de casa para viver nas ruas por motivos similares. Este tema exige múltiplos olhares nas complexidades sóciopsicológicas.

Assim, observa-se como há múltiplas e caleidoscópicas visões, bem como inúmeros e inesperados personagens no tema do abuso sexual intrafamiliar.

\section{Adultos sexualmente disfuncionais e suas crian- ças traumatizadas}

Sofremos os efeitos duradouros de exigências genitais ativas e passivas "obrigatórias" impostas a crianças pequenas... a menina pergunta: o mundo é perverso ou sou eu que estou errada? os meninos tomam para si tarefas super humanas. (FERENCZI, 2008.)

Muitas vezes é apenas na idade adulta que estes segredos são finalmente revelados, com traumas e sequelas ligadas a sensações de desamparo, de impotência e apresentando emocionalidades infantis. É importante que o terapeuta sexual pesquise traumas desta ordem em pessoas com queixas de disfunções sexuais.

Meu pai mudava muito de cidade por causa do emprego. Fomos morar em muitos países. As empregadas ficavam com a gente, porque minha mãe viajava muito com ele. Uma delas me ensinava a "lamber" a vagina dela e dizia que era para eu aprender a ser homem. Foi dos 4 aos 10 anos assim. Com meus irmãos também.

Esta é uma narrativa da quinta sessão de psicoterapia EMDR de Antônio (nome fictício), com 40 anos e executivo; que veio para a psicoterapia com queixa de ejaculação prematura secundária. Na sua vigésima sessão de psicoterapia EMDR, Antônio relatou:

Eu fiz um caminho difícil. Também tive vício em pornografia e masturbação. Era muito intenso. Não duvido que sou homem. Mas tenho que me controlar. Se não, a ansiedade me pega. Agora posso focalizar as sensações, estar com a pessoa que está comigo, que me ama, me respeita. Posso controlar a minha ejaculação bem melhor.

Sempre que possível recomendam-se tratamentos psicoterapêuticos e/ou médicos aos indivíduos abusados e a suas famílias. Obviamente os abusadores devem ser igualmente tratados, além das medidas legais a que poderão ser submetidos. Não se pode pensar em tratar um problema complexo com soluções simples, de causalidades lineares e terapêuticas reducionistas.

Não são abusivas apenas relações com diferenças de cinco anos de idade, lembrando que pessoas com mais idade poderão sofrer abusos de outras, com menor idade, como em situações de abuso sexual de idosos familiares.

Os comportamentos abusivos sexuais intrafamiliares tendem a ser mantidos em segredo. Por diferentes razões: por parte da vítima, pelo fato de obter algumas vantagens adicionais como presentes, dinheiro, entre outros; ou o medo de não ser acreditado ou ser acusado de sedução, juntamente com o receio de destruir a família ou de represálias do agressor. É importante garantir uma relação terapêutica sem julgamentos, para que os pacientes possam ser entendidos nesse processo de aparentes "ganhos secundários" na relação secreta com seus abusadores. Por parte destes, pela perda de atividade sexual que pode tornar-se aditiva, bem como a possível quebra do casamento e a rejeição familiar e social, até mesmo acompanhada por sanções legais.

A mãe (co-abusadora), muitas vezes, sabe o que acontece, mas também não denuncia por 
ter medo do marido ou de perder ou desestruturar a família e, em outras vezes, pelo estigma social negativo gerado pelo abuso sexual.

Alexandre (nome fictício), 58 anos e advogado, que veio à psicoterapia com queixa de ejaculação prematura, relatou em uma sessão de psicoterapia EMDR:

Eu vejo o meu treinador de futebol no acampamento. Ele era meu ídolo, mas eu já ficava com o coração acelerado quando ele me olhava. Sabia que viria aquilo. Ele me penetrava. Eu tinha dor e sufocava. Para quem eu ia contar? la ser o "viadinho" da turma? Ninguém iria acreditar! Ele era adorado por todos! Uma vez contei para minha mãe, ela me deu uma bronca, disse que eu era louco. Eu tinha 9 anos!

O abuso sexual pode ser levado à tona de forma acidental quando a vítima decide revelar ou, às vezes, conta para outra criança, um professor ou quando o comportamento sexual é descoberto.

A descoberta de abuso geralmente ocorre muitos meses ou anos depois dos primeiros incidentes. O processo de revelação por parte da criança ou do adolescente geralmente segue quatro fases progressivas: a negação, a revelação, a retirada da revelação e a reafirmação, na qual, após uma distância temporária, a criança e o adolescente novamente sustentam a declaração anterior sobre o abuso experimentado. Esse processo relativamente frequente, no entanto, é meramente indicativo e não está presente em todos os casos. Há pacientes adultos que temem revelar o segredo do abuso sexual intrafamiliar temendo "trair" a memória do abusador.

Finkelhor (1988) propõe o modelo traumatogênico, segundo o qual os motivos explicativos do impacto psicológico são os seguintes: sexualização traumática, perda de confiança, indefesa e estigmatização. Essas quatro variáveis são as principais causas do trauma, distorcendo o autoconceito, a visão do mundo e as capacidades emocionais dos abusados. Esses fatores estão relacionados, por sua vez, ao desenvolvimento da criança, do estilo de enfrentamento inadequado e do surgimento de problemas comportamentais na fase adulta como anorgasmia, ejaculação prematura secundária, entre outras.

O abuso sexual na infância cumpre os requisitos de trauma exigidos pelo Manual de
Diagnóstico e Estatística de Transtornos Mentais (DSMV) para o diagnóstico de Transtorno de Estresse Pós-Traumático (TEPT), que pode se apresentar com sintomas dissociativos; e/ou com expressão tardia de acordo com a Associação Psiquiátrica Americana (2014) e gera, pelo menos na maioria dos abusadores, os sintomas característicos desta doença: pensamentos intrusivos, evasão de estímulos relacionados à agressão, alterações do sono, irritabilidade e dificuldade de concentração. A desordem também inclui medo, ansiedade, depressão e sentimentos de culpa. Ao contrário dos adultos, nas crianças este quadro clínico pode assumir a forma de comportamento não estruturado ou agitado e apresentar sintomas físicos como dores de estômago e enxaquecas entre outros, ou sob a forma de sonhos aterrorizantes (ECHEBURÚA et al., 2015). Se esse quadro clínico se manifestar e se os mecanismos cognitivos adequados para superá-lo não forem usados (HARTMAN; BURGESS, 1993), o trauma permanece na memória ativa da criança devido ao processamento inadequado da informação. Depressão, culpa - referente à desunião familiar gerada pela divulgação do sigilo -, problemas sexuais, estado de confusão e distorções nas crenças sobre si mesma e outros sintomas são as sequelas que aparecem mais frequentemente em adultos abusados.

A perda de confiança pode se concentrar na relação com o abusador e também generalizar na relação com o restante da família. A estigmatização é sentida como culpa, vergonha e perda de valor. Essa série de conotações negativas são incorporadas à autoimagem da criança e do adolescente e exerce uma profunda influência na autoestima, o que pode levar à identificação com outros níveis estigmatizados da sociedade, como toxicodependência e prostituição. A manutenção secreta do abuso sexual pode reforçar a ideia de ser diferente e, assim, aumentar o sentimento de estigmatização (CORTÉS; CANTÓN, 2007).

O sentimento de desamparo traduz-se na criança e no adolescente em uma crença de não saber como reagir às várias situações na vida real e em ter pouco controle sobre si mesmo e o que acontece com ele(a). Tudo isso cria na pessoa abusada uma sensação de desproteção, abandono e medo do que pode acontecer no futuro, provocando atitudes passivas e não assertivas. Muito frequentemente isso se refere nas escolhas inconscientes de parceiros e cônjugues abusivos na vida adulta. 
Nem todas as pessoas reagem da mesma maneira às experiências de abuso sexual intrafamiliar e nem todas as experiências traumáticas compartilham as mesmas características. Há pelo menos quatro grupos de variáveis: o perfil da pessoa abusada quanto à idade, ao sexo e ao contexto familiar; as características do ato abusivo como: frequência, gravidade, existência de violência ou ameaças e cronicidade; o relacionamento existente com o abusador; e as consequências associadas à descoberta de abuso.

Em relação às características do ato abusivo, a gravidade das sequelas depende da frequência e duração da experiência, bem como do uso da força e ameaças ou a existência de alguma violação como: penetração vaginal, anal ou bucal. Dessa forma, quanto mais crônico e intenso é o abuso sexual, maior é o desenvolvimento de um sentimento de desamparo e vulnerabilidade; assim os sintomas mais prováveis aparecem. Quanto à relação da vítima com o agressor, o que importa não é tanto o grau de parentesco entre ambos, mas o nível de intimidade emocional entre eles. Quanto maior a privacidade, maior o impacto psicológico, o que pode ser agravado se a pessoa abusada não receber apoio da família ou for forçada a deixar o lar.

A evolução psicológica da pessoa abusada afeta especialmente sua autoestima e dependerá de algumas variáveis: as dúvidas levantadas pelo testemunho; o significado afetivo das pessoas incrédulas e a falta de apoio emocional e social. Sentimentos de vergonha, culpa, raiva, tristeza, medo e ansiedade podem afetar os pais de tal forma que são incapazes de proteger a criança corretamente e, nos casos mais sérios, podem até culpá-la pelo que aconteceu. A possível ruptura do casal, a saída do abusador ou da vítima do lar e o envolvimento em um processo judicial são exemplos dessas situações. Julgamentos longos e testemunhos repetidos é uma possibilidade de vitimização secundária e oferecem pior prognóstico.

O fenômeno observado mais regularmente em adultos sexualmente abusados na infância em relações intrafamiliares são: alterações na inibição sexual erótica, disfunção sexual, menor prazer, depressão, o conjunto de sintomas característicos do TEPT, bem como um controle inadequado da raiva $\mathrm{Em}$ alguns casos, uma atitude obsessiva e hipervigilante em relação às crianças foi detectada no longo prazo quando se tornam pais ou, pelo contrário, a adoção de atos de abuso ou, pelo menos, consentimento (SEPÚLVEDA; SEPÚLVEDA, 1999). No entanto, esses aspectos relativamente frequentes também não constituem um fenômeno universal (NOGUEROL, 1997). Fernando, com 43 anos e dentista em uma sessão de psicoterapia EMDR, relatou:

Eu esqueci de que aquilo podia fazer sofrer. Ficava hipnotizado. Ficar a sós com a minha sobrinha já me excitava. Quando eu me masturbava nas perninhas dela, sentia um alívio no peito. É uma loucura isso, eu sei.

Como incluir todas as crenças no trabalho psicoterápico com pessoas abusadas sexualmente por seus familiares? O DSM não é escritura sagrada; diagnostica os transtornos da vida, não o seu significado. O humanismo nos ensinou a pensar que algo só pode ser ruim se levar alguém a se sentir mal. Nossos sentimentos proveem significado não somente a nossa vida privada, mas também a processos sociais e políticos. Sugerimos essas reflexões quando alguns pacientes trouxeram seus sentimentos complexos na busca de uma psicoterapia sexual. Tratar somente com técnicas sexuais um paciente traumatizado por abusos, portanto, poderá ser ineficaz.

Em resumo: é muito importante conhecer as crianças sexualmente abusadas e traumatizadas em seus egos adultos para sugerir o tratamento mais adequado a elas.

\section{Psicoterapia EMDR para o âmbito sexual}

O abuso sexual é um evento traumatogênico que, como no caso de outros eventos negativos que uma criança ou adolescente pode sofrer, pode produzir disfunções sexuais na vida adulta a curto e longo prazo. (FINKELHOR, 1988)

Os seres humanos têm distintos sentimentos, gostos e peculiaridades, e deveríam ser livres para expressá-los e explorá-los, contando que com isso não fira os de outrem. Os traumas ligados a abusos sexuais intrafamiliares podem dificultar sobremaneira a expressão destes sentimentos. A psicoterapia EMDR busca reprocessar experiências vividas traumáticas.

Uma experiência é um fenômeno subjetivo que inclui três fatores: sensações, emoções e pensamentos. Sensibilidade é prestar atenção às nossas sensações, às nossas emoções e aos nossos pensamentos e permitir que exerçam influência sobre nós. Experiências e sensibilidade 
incrementam-se reciprocamente num ciclo interminável.

A psicoterapia EMDR tem sido usada para melhorar a regulação afetiva e alterar características de personalidade (BROWN; SHAPIRO, 2006), diminuir a dor do membro fantasma (SCHNEIDER; HOFMANN; ROST; SHAPIRO, 2008) e queixas somáticas (GUPTA; GUPTA, 2002); melhorar a depressão em adolescentes (BAE; KIM; PARK, 2008) e tratar de problemas de ansiedade, fobias, perturbação de pânico e perturbação de ansiedade generalizada (DE JONGH; VAN DEN OORD; TEN BROEKE, 2002; FERNANDEZ; FARETTA, 2007; GAUVREAU; BOUCHARD, 2008). A principal vantagem desta abordagem terapêutica sobre a clássica terapia cognitivo-comportamental é a rapidez da sua ação e menor número de sessões envolvidas (DE JONGH; TEN BROEKE, 2007; DE JONGH ET AL., 2002; ROOS; DE JONGH, 2008).

Usamos o modelo do Sistema de Processamento Adaptativo de Informação, como base teórica da psicoterapia EMDR, que se baseia no conhecimento de que existe um sistema fisiológico de processamento de informações mediante o qual as novas experiências e informações se processam para obter um estado adaptativo. Essas informações se armazenam em redes de memória com pensamentos, imagens, emoções e sensações vinculadas entre si (ZAMPIERI, 2016). As redes de memória se organizam em torno do conhecimento mais precoce vinculado a esse grupo (HENSLEY, 2010). As experiências traumáticas e as necessidades interpessoais insatisfeitas, de forma persistente, podem produzir bloqueios na capacidade do sistema de processamento adaptativo da informação, para resolver eventos traumáticos, gerando reações disfuncionais, como por exemplo, anorgasmia e ejaculação prematura secundárias. Os procedimentos da psicoterapia EMDR promovem a redução da intensidade de memórias perturbadoras e seus afetos vinculados, o que facilita o acesso a informações mais adaptativas, bem como novas associações dentro das redes de memória (SHAPIRO, 2001).

A psicoterapia EMDR ajuda a desbloquear o sistema nervoso, permitindo que o cérebro processe a experiência traumática. O terapeuta executa a estimulação bilateral que favorece a comunicação entre os dois hemisférios cerebrais através de movimentos laterais oculares, sons alternados, ou toques nas mãos ou nos joelhos; enquanto o paciente acede simultaneamente à memória traumática armazenada mediante as imagens, cognições, emoções e sensações (WESSELMANN et al., 2012).
É um processo semelhante ao que se passa quando sonhamos na chamada fase Rapid Eye Movement (REM) do sono, durante a qual os rápidos movimentos oculares facilitam o processamento do material inconsciente. Quando surge uma situação traumática, essa fase pode ficar bloqueada no sistema nervoso com a recordação original, os sons, os pensamentos, as emoções do passado e as sensações físicas. A psicoterapia EMDR permite que a pessoa identifique e separe as sensações afetivas do trauma das suas interpretações cognitivas, ajudando-a a dessensibilizar as memórias traumáticas (ZAMPIERI, 2016).

É uma abordagem de oito etapas específicas desde a história clínica do paciente, a preparação para o protocolo, a avaliação, a dessensibilização e o reprocessamento da memória traumática, fechamento e follow-up (WESSELMANN et al., 2012). Ao longo desse processo são trabalhados os eventos passados que estabelecem as bases para a patologia, as situações atuais que causam perturbação e futuros modelos para a ação apropriada ou adequada (SHAPIRO, 2005).

Baseando-se no protocolo da psicoterapia EMDR, as situações emocionalmente difíceis do passado são reprocessadas, bem como os estímulos disparadores atuais, que provocavam dificuldades para que a pessoas consiga estar perante os objetos indutores de ansiedade. A instalação de recursos de autoestabilização e os entrelaçamentos cognitivos usados são técnicas poderosas que proporcionam avanços no processo terapêutico. Quando esses entrelaçamentos são aplicados, abre-se a possibilidade de introduzir novas perspectivas ao sistema de processamento na busca de facilitar um reprocessamento satisfatório ao se cruzarem com outras redes de memória e associações mais adaptativas do paciente. Um exemplo de entrelaçamento cognitivo, seria perguntar à paciente Maria (nome fictício), com 42 anos, que se sente bloqueada sexualmente por associar relação sexual com seu marido com abusos sexuais sofridos na infância: "Imagine-se olhando agora para essa cena em que se sente culpada pelo abuso de seu avô. O que, com a sua idade atual, você poderia fazer para defender-se?". O terapeuta auxiliaria a paciente a recuperar o presente, que está em seu ego adulto.

As sessões podem ter periodicidade semanal, tendo cada uma a duração de 60 a 90 minutos. O uso dessa psicoterapia com disfunções sexuais ligadas a abusos sexuais intrafamiliares mostrou-se eficaz em cerca de 20 a 40 sessões, 16 indo ao encontro de várias pesquisas que 
conseguiram tais resultados eficazes (DE JONGH; TEN BROEKE, 1998; DE JONGH ET AL., 2002; ROOS; DE JONGH, 2008).

Os pacientes cronicamente abusados podem apresentar o que chama-se de trauma complexo. Quando isso ocorre, é importante identificar e tratar as três áreas: recordações-chaves do passado, estímulos disparadores do presente e possibilidades comportamentais do futuro.

Veja-se, como ilustração, uma das sessões de psicoterapia EMDR de Maria, a paciente citada anteriormente. Em uma das lembranças do abuso sexual do avô paterno, ela trouxe a cena:

Vejo meu avô me levando para o escritório da minha casa de infância. Eu devia ter uns oito anos. Ele está sentado comigo em um sofá marrom. Na televisão passa um programa de esportes. Lembro da música. Ele está com o pênis para fora da calça e me coloca no colo dele e faz "cavalinho". Lembro do cheiro dele.

A paciente relata ter a crença negativa sobre esse evento quando afirma: "Eu sou culpada". E apresenta um grau de perturbação nível 10 Subjective Units of Distress Scale (SUDS), em uma escala de 0 a 10 (ZAMPIERI, 2016).

Com relação aos estímulos disparadores no presente, em outra sessão de psicoterapia EMDR, a paciente trouxe a cena de estar com seu marido em uma situação de intimidade sexual quando ele pediu que ela o masturbasse. Ela relatou: "Sinto a mesma raiva que desenvolvi por meu avô. E me sinto culpada. Se estou ali, por que ele precisa da masturbação?". Relata emoção de impotência, com sensações físicas de desconforto na região do diafragma.

No que se refere a situações futuras, Maria trouxe uma cena imaginária em que o marido a estimulava no clitóris e onde pudesse "presentificar" essa sensação, sem misturar com as cenas de estimulação do avô abusivo. Trabalhou-se a cena como ela gostaria de se ver lidando com a situação em um futuro breve.

Trauma complexo por abuso sexual intrafamiliar crônico é caracterizado por uma complexidade de abusos vivenciados por um período prolongado e, às vezes, com dissociações.

No exemplo de Maria, muitas vezes ela revivia as relações abusivas com o avô e sentia-se como se "uma máquina do tempo" a levasse para o passado.

Eu me esquecia que estava com meu marido, e vinham as sensações da minha infância embaixo da mesa na sala de jantar; brincando de "cosquinhas" com o meu avô. (Maria, em uma sessão de psicoterapia EMDR).

Nessa psicoterapia é importante que os eventos de memórias mais precoces, ligadas ao abuso sexual intrafamiliar, sejam tratados. Eles podem surgir esporadicamente ou com técnicas de checagem de emoções e de sensações físicas. É possível pesquisar quando foi a primeira vez que a paciente se lembra, por exemplo, de ter sentido aquelas emoções. Maria disse se lembrar da cena mais remota, a ocasião em que tinha 8 anos de idade quando o avô a estimulava e a manipulava enquanto tomava banho e lavava seus órgãos genitais com o chuveirinho. Esse evento trouxe à tona a crença negativa de que ela era culpada, com a referente emoção de impotência.

Com Maria, o tratamento psicoterápico sexual, que durou 36 sessões, teve a meta atingida; usando-se também a psicoterapia sexual clássica (LEIBLUM, 2012) e psicoeducação sexual. As memórias do passado não mais invadiam suas experiências sexuais presentes e ela deixou de apresentar ansiedade antecipatória quando pensava na possibilidade de ter relação erótica e sexual com seu marido.

É importante lembrar que o terapeuta que se utiliza da psicoterapia EMDR deve estar atento à possibilidade de o paciente manter a atenção dual, passado e presente, durante as aplicações do protocolo EMDR.

As melhorias com a psicoterapia EMDR vão além dos sintomas evidentes provocados pela situação traumática. A instalação de recursos de autocontrole revela-se muito útil, pois empodera os pacientes após o processamento da EMDR, fornecendo-Ihe ferramentas para lidar com memórias traumáticas e adquirir novas aprendizagens, indo ao encontro das constatações de Shapiro e Luber (2009). Dessa forma a terapia EMDR pode ser uma alternativa eficaz para o tratamento de disfunções sexuais, com etiologia traumática por abusos sexuais intrafamiliares.

\section{Reflexões finais}

"Aqui estão as raízes do trauma. A desconexão de nossa sensopercepção de pertencer faz com que nossas emoções flutuem num vácuo de solidão. Ela faz com que nossa mente racional crie 
fantasias baseadas na desconexão e não na conexão. Essas fantasias nos levam a competir, guerrear, desconfiar dos outros, e sabotam nosso respeito natural pela vida. Os seres humanos são naturalmente cooperativos e amorosos. Entretanto, sem o cérebro plenamente integrado, não podemos nos reconhecer quanto a isto." (LEVINE, 1999)

Acredita-se que o maior desafio e responsabilidade dos profissionais de saúde mental é promover psicoeducação preventiva do abuso sexual intrafamiliar para pais, mães, filhos, professores e educadores da saúde em geral.

A psicoterapia EMDR favorece as elaborações psíquicas, que chamamos de funções cometabolizadoras (ZAMPIERI, 2016). Quando se trata de pessoas traumatizadas por abusos sexuais intrafamiliares, podemos é possível, contextualizadamente, ajudá-las a transformar emoções e sensações físicas, especialmente de medo, desespero, incapacidade, insegurança, injustiça, indefesa e falta de ar, com base em crenças negativas e limitantes; em emoções de alívio, paz, calma, confiança e com as crenças de ser capaz e poder lidar com a vida, mais abertos aos suportes familiares, sociais e espirituais (ZAMPIERI, 2016). Assim, essas pessoas terão chances, por meio do processo adaptativo de informação (SHAPIRO, 2012), de retomar a capacidade psíquica de associar afeto com representação (BENYAKAR, 2005). Essa psicoterapia permite um acesso ao psiquismo que possibilita relacionar recordações de abusos sexuais intrafamiliares e vida sexual da vida adulta, com novas articulações entre afeto e representação (ZAMPIERI, 2016).

Como exemplo, Maria, em uma de suas últimas sessões de EMDR, narrou:

Meu corpo sente prazer em ter prazer espontâneo e respeitado por mim. Sou uma mulher que posso lutar e dizer não, se eu for invadida ou abusada. Isso ficou no passado. Eu posso me entregar e experimentar sem culpas ou fantasmas. Eu posso cuidar de mim...

Nessa afirmação é possível constatar como a terapia EMDR possibilitou associação entre memórias corporais, sensuais e eróticas com a diminuição de crenças negativas autorreferentes e valorização das positivas, o que impacta a rearticulação afeto com representação (ZAMPIERI, 2016).
Quando adultos finalmente revelam os abusos sexuais a que foram submetidos e identificam e reprocessam essas vivências traumáticas, poderão ser empoderados para a chance de uma vida sexual ativa, saudável e prazerosa e, ainda, podem quebrar o ciclo da traumatização transgeracional, quando abusados tornam-se abusadores.

A psicoterapia EMDR é, portanto, eficaz e comprovadamente indicada. Como fenômeno sistêmico, essa indicação deve ser oferecida a todos os personagens do cenário do abuso sexual intrafamiliar: abusadores, coabusadores, abusados e todas as pessoas direta e indiretamente ligadas a essa trama traumatogênica.

Para resolver o trauma é preciso aprender a nos mover fluidamente entre o instinto, a emoção e o pensamento racional. Quando essas três fontes estão em harmonia, comunicando sensação, sentimento e cognição, nosso organismo funciona mais harmonicamente. A psicoterapia EMDR está aqui referendada para a clínica do terapeuta sexual que lida com traumas por abusos sexuais intrafamiliares, muitas vezes pano de fundo de disfunções sexuais.

\section{Referências}

AMERICAN PSYCHIATRIC ASSOCIATION. Practice guideline for the treatment of patients with acute stress disorder and post-traumatic stress disorder. Arlington: American Psychiatric Association Practice Guidelines, 2004.

AMERICAN PSYCHIATRIC ASSOCIATION. Referência rápida aos diagnósticos do DSM-V. Porto Alegre: Artmed, 2014.

BAE, H.; KIM, D.; PARK, Y. C. Eye movement desensitization and reprocessing for adolescent depression. Psychiatry Investigation, n. 5, p. 6065, 2008.

BENYAKAR, M. Lo Traumático Clínica e Paradoja - Tomo 1: El proceso traumático. Bueno Aires: Editorial Biblos, 2005.

BISSON, J.; EHLERS, A.; MATTEWS, R.; PILLING, S.; RICHARDS, D.; TURNER, S. Psychological treatments for chronic post-traumatic stress disorder: systematic review and meta-analysis. The British Journal of Psychiatry, n. 190, p. 97-104, 2007. 
BRASIL, Portal. Dia Nacional Contra Abuso Sexual de Crianças e Jovens é celebrado nesta quinta (18). Disponível em: <http://www.brasil.gov.br/ cidadania-e-justica/2017/05/dia-nacional-contra-abuso-sexual-de-criancas-e-jovens-e-celebrado-nesta-quinta-18>. Acesso em: 06 set. 2017.

BROWN, S.; SHAPIRO, F. EMDR in the treatment of borderline personality disorder. Clinical Case Studies, n. 5, p. 403-420, 2006.

CORTÉS, M. R.; CATÓN, J. Malos tratos y abuso sexual infantil. Madrid: Siglo XXI, 2007.

DE JONGH, A.; TEN BROEKE, E. Treatment of choking phobia by targeting traumatic memories with EMDR: a case study. Clinical Psychology \& Psychotherapy. Nova York, n. 5, p. 264269, 1998.

DE JONGH, A.; TEN BROEKE, E. Treatment of specific phobias with EMDR: conceptualization and strategies for the selection of appropriate memories. Journal of EMDR Practice and Research. Austin, v. 1, n. 1, p. 46-57, 2007.

DE JONGH, A.; VAN DEN OORD, H. J.; TEN BROEKE, E. Efficacy of eye movement desensitization and reprocessing (EMDR) in the treatment of specific phobias: four single-case studies on dental phobia. Journal of Clinical Psychology, 58(12), 2002, p. 1489-1503.

DEPARTMENT OF VETERANS AFFAIRS AND DEPARTMENT OF DEFENSE. Clinical practice guideline for the management of post-traumatic stress. Washington: Veterans Health Administration, Department of Veterans Affairs and Health Affairs, Department of Defense, 2010.

ECHEBURÚA, E. Evaluación y tratamiento de la fobia social. Barcelona: Martínez Roca, 2015.

ECHEBURÚA, E.; GUERRICAECHEVARRÍA, C. Abuso sexual en la infancia: víctimas y agresores. Barcelona: Ariel, 2000.

ETTEN, M., TAYLOR, S. Comparative efficacy of treatments for post-traumatic stress disorder: a meta-analysis. Clinical Psychology and Psychotherapy, n. 5, p. 126-144, 2008.

FERENCZI, S. Sin simpatía no hay curación: el diario clínico de 1932. $2^{a}$ ed. Bueno Aires: Amor- rortu, 2008.

FERNANDEZ, I.; FARETTA, E. EMDR in the treatment of panic disorder with agoraphobia. Clinical Case Studies, n. 6, p. 44-63, 2007.

FINKELHOR, D. Sexually victimized children. Nova York: Free Press, 1979.

FINKELHOR, D. The trauma of child sexual abuse: two models. In: WYATT, G. E.; POWELL, G. J. (Ed.). Lasting effects of child sexual abuse. Newbury Park: SAGE Publications, 1988.

FINKELHOR, D.; ASDIGIAN, N. L. Risk factors for youth victimization: beyond a lifestyles theoretical approach. Violence and Victims, n. 11, p. 3-20, 2006.

FOA, E. B.; KEANE, T. M.; FRIEDMAN, M. J.; COHEN, J. A. Effective treatments for PTSD: practice guidelines of the international society for traumatic stress studies. Nova York: Guilford Press, 2009.

GAUVREAU, P.; BOUCHARD, S. P. Preliminary evidence for the efficacy of EMDR in treating generalized anxiety disorder. Journal of EMDR Practice and Research, n. 2, p. 26-40, 2008.

GUPTA, M.; GUPTA, A. Use of eye movement desensitization and reprocessing (EMDR) in the treatment of dermatologic disorders. Journal of Cutaneous Medicine and Surgery, n. 6, p. 416421, 2002.

HARARI, Y. N. Homo Deus. uma breve história do amanhã. São Paulo: Companhia das Letras, 2016.

HARTMAN, C. R.; BURGESS, A. W. Sexual abuse of children: causes and consequences. In: CICCHETTI, D.; CARLSON, V. (Ed.). Child maltreatment: theory and research on the causes and consequences of child abuse and neglect, Cambridge: Cambridge University Press, 1993.

HENSLEY, B. J. Manual básico de EMDR. Bilbao: Desclée De Brouwer, 2010.

HERMAN, J.; RUSSELL, D.; TROCKI, K. Long-term effects of incestuous abuse in childhood. American Journal of Psychiatry, n. 143, p. 12931296, 2006. 
INTEBI, I. V. Abuso sexual infantil: en las mejores familias. Bueno Aires: Ediciones Granica SA, 2008 LAWSON, C. Mother-son sexual abuse: rare or underreported? A critique of the research. Child Abuse and Neglect, n. 17, p. 261-269, 2013.

LEIBLUM, S. R. Tratamento dos transtornos do desejo sexual: casos clínicos. Porto Alegre: Artmed Editora, 2009.

LEVINE, P. A.; FREDERICK, A.; LEVINE, P. A. O despertar do tigre: curando o trauma. Grupo Editorial Summus. 1990.

LUBER, M. EMDR scripted protocols. New York: Spinger. 2009.

MacCARTHY, B. W. Acercamiento cognitivo-conductual al tratamiento de famílias incestuosas. In: STICH, S. M.; WILLIANMS, M. B.; ROSEN, K. (Ed.). Psicosociología de la violencia en el hogar. Bilbao: Descleé de Brower, 2002.

NOGUEROL, V. Aspectos psicológicos del abuso sexual infantil. In: CASADO, J.; DÍAS, J. A.; MARTíNEZ, C. (Ed.), Niños maltratados. Madrid: Días de Santos, 1997.

ROOS, C.; DE JONGH, A. EMDR treatment of children and adolescents with a choking phobia. Journal of EMDR Practice and Research, v. 3, n. 2, p. 201-211, 2008.

ROSSEAU, J. J. Emílio ou da educação. Rio de Janeiro: Bertrand Brasil, 1995.

SCHNEIDER, J.; HOFMANN, A.; ROST, C.; SHAPIRO, F. EMDR in the treatment of chronic phantom limb pain. Pain Medicine, n. 9, p. 76-82, 2008.

SEPÚLVEDA, A; SEPÚLVEDA, P. Abusos sexuales a menores. Sevilla. Asociación de Asistencia a Victímas de Agresiones Sexuales. Madrid: Editora Paidós, 1999.

SHAPIRO, F. EMDR Eye Movement Desensitization and Reprocessing. Rio de Janeiro: Nova Temática, 2001.

SHAPIRO, F. The EMDR approach to psychotherapy. Watsonville: EMDR Institute, 2009.

SHAPIRO, F. EMDR solutions: pathways to hea- ling. Nova York: Norton \& Company, 2005. SHAPIRO, F.; KASLOW, F. K.; MAXFIELD, L. Manual de EMDR y Processos de Terapia Familiar. Espanha: Ediciones Pléyades, 2012.

VAN DER KOLK, B.; SPINAZZOLA, B.; BLAUSTEIN, M. E.; HOPPER, J. W.; HOPPER, E. K.; KORN, D. L.; SIMPSON, W. B. A randomized clinical trial of eye movement desensitization and reprocessing (EMDR), Fluoxetine, and Pill placebo in the treatment of posttraumatic stress disorder: treatment effects and long-term maintenance. Journal of Clinical Psychiatry, n. 68, p. 1-10, 2007.

WESSELMANN, D; DAVIDSON, M; ARMSTRONG, S; SCHWEITZER, C; BRUCKNER, D; POTTER, A. E. EMDR as a treatment for improving attachment status in adults and children. Revue Européenne de Psychologie Appliquée, n. 62, p. 223230, 2012.

ZAMPIERI, A. M. F. Erotismo, sexualidade, casamento e infidelidade: sexualidade conjugal e prevenção do HIV e da AIDS. São Paulo: Editora Agora, 2004.

ZAMPIERI, A. M. F. Psicodrama em espaços públicos. São Paulo: Editora Agora, 2014.

ZAMPIERI, A. M. F. Aportes teóricos de Lo Disruptivo al EMDR con damnificados de catástrofes naturales en Brasil. Tese (Doutorado). USAL, Bueno Aires, 2016. 